Article

\title{
Apoptosis Induction by dsRNA-Dependent Protein Kinase $R$ (PKR) in EPC Cells via Caspase 8 and 9 Pathways
}

\author{
Cheng Xu, Amr A. A. Gamil ${ }^{\mathbb{D}}$, Hetron Mweemba Munang'andu ${ }^{\circledR}$ and $\varnothing_{\text {ystein Evensen * }}$ \\ Faculty of Veterinary Medicine, Norwegian University of Life Sciences, PO Box 369, 0102 Oslo, Norway; \\ cheng.xu@nmbu.no (C.X.); amr.gamil@nmbu.no (A.A.A.G.); \\ hetroney.mweemba.munangandu@nmbu.no (H.M.M.) \\ * Correspondence: oystein.evensen@nmbu.no; Tel.: +47-47400119
}

Received: 3 August 2018; Accepted: 25 September 2018; Published: 27 September 2018

check for updates

\begin{abstract}
RNA-dependent protein kinase R (PKR) is an interferon-inducible protein that mediates antiviral effects and induces apoptosis. We studied PKR-related apoptosis mechanisms by transfecting wild type pcDNA-carp-wtPKR, a catalytically inactive mutant pcDNA-mut-carpPKR, and empty plasmid in Epithelioma papulosum cyprini (EPC) cells, designated wtPKR, mutPKR, and pcDNA3.1, respectively. PKR was inefficiently expressed from wtPKR unlike mutPKR that produced high PKR levels detected by western blot. eIF2 $\alpha$ phosphorylation increased in wtPKR-transfected cells, while for mutPKR, phosphorylation was not different from non-transfected controls. Flow-cytometry revealed high level of apoptosis in wtPKR transfected cells, corresponding with high cytopathic effect. mutPKR and pcDNA3.1 transfection gave significantly less apoptosis and were not different from each other. Caspase- 8 and -9 were activated for wtPKR, suggesting death receptor-caspase- 8 and mitochondrion-dependent caspase-9 activated pathways, similar to mammalian cells. These findings suggest that the induction of apoptosis via the caspase- 8 and -9 pathways are conserved in vertebrate taxa and likely play a role in viral infections of lower vertebrates.
\end{abstract}

Keywords: apoptosis; annexin-V; caspase 8 and 9; eIF2alpha; phosphorylation; PKR

\section{Introduction}

Type I interferon (IFN) response is the major innate immune defense mechanism against viral infection. Production of type I IFN is stimulated by recognition of invading viruses through different host sensors [1]. Once secreted, type I IFN binds to its receptor on the cell surface in an autocrine or paracrine manner and triggers a signaling cascade through the Janus kinase/signal transducer and activator of transcription proteins (JAK/STAT) pathway [2,3]. Induction of different IFN-stimulated genes (ISGs) leads to the establishment of an antiviral state in host cells [4]. The dsRNA activated protein kinase $\mathrm{R}$ (PKR) is an ISG constitutively expressed in nearly all mammalian cells and is activated by the binding of dsRNA to dsRNA-binding motifs (dsRBMs) at its N-terminus [5-7]. Activated PKR undergoes dimerization, which subsequently promotes autophosphorylation to produce the active form [8]. The best known function of the activated PKR is the control of protein translation via phosphorylation of the alpha subunit of eukaryotic initiation factor 2 (eIF2 $\alpha$ ), whose main function is inhibition of protein synthesis in order to prevent viruses from producing new progeny [9]. eIF2 $\alpha$ is the primary substrate of PKR and its phosphorylation correlates with the induction of programmed cell death that renders it to serve as a molecular determinant of apoptosis [10]. PKR has been identified, cloned, and characterized in several fish species such as olive flounder (Paralichthys olivaceus) [11], zebrafish (Danio rerio) [12], crucian carp (Carassius carassius) [13], and rock bream (Oplegnathus 
fasciatus) [14]. In addition, it has been shown to phosphorylate eIF2 $\alpha$ and its antiviral properties have been demonstrated in flounder and carp [11,15]. As part of the antiviral responses, PKR mediates cellular apoptosis but can also induce apoptosis in the absence of a virus infection [5]. There are studies on the involvement of PKR as part of a viral infection in fish [16,17] but few addressing the induction of apoptosis as an integral part of the antiviral response. Hu et al. [17] allude to the cellular responses mediated by PKR and eIF2 $\alpha$ phosphorylation but did not perform any analysis to confirm this. Induction of apoptosis in fish cells in the absence of viral infection remains unexplored.

There are two major apoptosis pathways: (i) the extrinsic pathway commonly referred to as the "death receptor-mediated pathway"; and (ii) the intrinsic mitochondrial pathway $[18,19]$. The extrinsic pathway uses transmembrane death receptors that are members of the tumor necrosis factor (TNF) genes superfamily, that share a similar-cysteine-rich extracellular domain called the "death domain" [20]. This domain transmits death signals from the cell surface to intracellular ligands to the apoptosis cellular machinery. The best characterized death receptor-mediated interaction is the FS7-associated cell surface antigen (Fas) receptor-ligand interaction, and engagement leads to binding of the adapter protein Fas-associated death domain (FADD) followed by formation of the death inducing complex (DISC) and auto-catalytic activation of caspase-8 [21]. The Intrinsic signaling pathway uses non-receptor mechanisms that activate the caspase dependent mitochondrial pathway where cytochrome $\mathrm{c}$ binds and activates the apoptosis protease activating factor (Apaf)-1 together with procaspase-9 to form a complex called "apoptosome" [22]. Involvement of procaspase-9 leads to activation of caspase- 9 that initiates the apoptosis execution phase by activating the downstream caspase cascade $[23,24]$. Ultimately, the caspase- 8 and -9 pathways converge on activating the terminator caspases, caspase- $3,-6$, and -7 that are executioners of apoptosis $[25,26]$. Caspase- 8 and -9 genes have been reported in fish [27-30] but their involvement in induction of apoptosis has not been explored. On this basis, we were interested in studying the mediation of PKR in apoptosis in the absence of a virus infection and we used an approach of PKR overexpression, monitored phosphorylation of eIF $2 \alpha$ and also included an assessment of involvement of caspase- 8 and -9 in the process. We find that PKR overexpression in Epithelioma papulosum cyprini (EPC) cells induces apoptosis following eIF $2 \alpha$ phosphorylation, and activation of caspase- 8 and -9 . These responses are ablated when transfecting with a PKR variant with a mutated, catalytically inactive domain.

\section{Materials and Methods}

\subsection{Cell Culture and Virus}

Epithelioma papulosum cyprini cells (EPC), Asian Grouper strain K (AGK) [31], and chinook salmon embryonic cells (CHSE) were all cultured in Leibovitz 15 (L-15) media, which was supplemented with $10 \%$ fetal bovine serum (FBS), L-glutamine, and gentamicin and maintained at $20{ }^{\circ} \mathrm{C}$ in L-15 medium (Invitrogen, Carlsbad, CA, USA) supplemented with 5\% FBS, l-glutamine, and gentamicin. A recombinant IPN virus (rNVI-015) produced by reverse genetics was used. The virus was inoculated into $70-80 \%$ confluent $\mathrm{CHSE}$ cells followed by incubation at $15^{\circ} \mathrm{C}$ and cultured until full cytopathic effects (CPE). The supernatant containing the virus was then harvested and clarified by centrifugation at $2500 \mathrm{rpm}$ for $10 \mathrm{~min}$. The concentration of the virus was estimated by titration in 96-well plates (Falcon, New York City, NY, USA). The obtained supernatant was used to infect CHSE cells to assess eIF2 $\alpha$ phosphorylation (described below 2.3) as positive control.

\subsection{Electroporation of Plasmids into EPC and AGK Cells}

Eukaryotic expression plasmid pcDNA-wtcarpPKR expressing the wild-typecarp PKR and pcDNA-mutcarpPKR expressing a catalytically inactive PKR having a single mutation Lys419Arg (K419R) in the catalytic domain were kind gifts from Professor Gui [15]. For overexpression of carp PKR proteins, EPC cells were transfected by electroporation with $2 \mu \mathrm{g}$ per $10^{6}$ cells of the wild type construct pcDNA-wtcarpPKR, the mutated form at the catalytic site pcDNA-mutcarpPKR or only the 
backbone plasmid pcDNA3.1-myc-His (Invitrogen, Carlsbad, CA, USA). Transfection was performed using the Neon transfection system (Invitrogen) with one pulse of $1200 \mathrm{~V}$ for $40 \mathrm{~ms}$. After transfection, cells were kept at $20^{\circ} \mathrm{C}$ for 3 days until further experiments. The three plasmids were designated wtPKR, mutPKR, and pcDNA3.1 corresponding to the pcDNA-wtcarpPKR, pcDNA-mutcarpPKR, and pcDNA3.1-myc-His, respectively.

\subsection{Western Blot}

Transfected cells were grown in 6-well plates and harvested for protein extraction. Cells were lysed using the CelLytic M reagent (Sigma-Aldrich, St. Louis, MO, USA) and scraped from the plates. Lysates were separated in 12\% NuPAGE Bis-Tris gels (Invitrogen) and transferred to the PVDF membrane using Trans-Blot SD semi-dry transfer cell (BioRad, Hercules, CA, USA). Membranes were blocked for $2 \mathrm{~h}$ using $5 \%$ dry milk in TBST (0.02 M Tris-HCl, $0.9 \% \mathrm{NaCl}, 0.05 \%$ Tween 20, pH 7.6). Polyclonal antibody against phosphorylated eIF2 $\alpha$ (p-eIF2 $\alpha$ ) (Invitrogen), actin (Sigma) and mouse anti-c-myc monoclonal antibody was diluted in $2.5 \%$ dry milk in TBST and incubated overnight at $4{ }^{\circ} \mathrm{C}$. Horseradish peroxidase (HRP) conjugated anti-rabbit or anti-mouse antibody (Cell Signaling, Danvers, MA, USA) diluted 1:2000 were added and incubated for $1 \mathrm{~h}$. Final detection was achieved using the ECL Plus ${ }^{\mathrm{TM}}$ Western Blotting (WB) detection reagents and a Typhoon scanner (Amersham Biosciences, Little Chalfont, UK).

Quantification of eIF2 $\alpha$ phosphorylation after transfection of pcDNA-wtPKR and pcDNA-mutPKR in EPC (2 experiments) and AGK cells (1 experiment) was done at 16, 24, and $40 \mathrm{~h}$ post transfection. The amount of p-eIF $2 \alpha$ measured by densitometry (Typhoon Imager, GE Healthcare, Chicago, IL, USA) was quantified with ImageJ software, and the value was normalized against $\beta$-actin levels.

\subsection{Apoptosis Assays}

Annexin V-FLUOS (Sigma-Aldrich) in combination with PI staining was used to determine phosphatidylserine (PS) exposure in apoptotic cells using the Annexin V-FLUOS/PI Staining Kit (Sigma-Aldrich). Briefly, cells were washed with phosphate buffered saline (PBS), trypsinized, centrifuged and resuspended in labeling solution containing fluorescein-conjugated Annexin $\mathrm{V}$ and PI. Thereafter, they were incubated for $15 \mathrm{~min}$ in the dark at room temperature. This was followed by flow cytometry using Guava easyCyte ${ }^{\mathrm{TM}}$ Flow Cytometer (Merck Millipore, Burlington, MA, USA) and InCyte ${ }^{\mathrm{TM}}$ software version 0.2 (Merck Millipore). These studies were done in 2 independent experiments.

\subsection{Measurement of Caspase-8 and -9 Activation}

Measurement of caspase-8 and -9 activation was performed using Caspase 8/9 (active) FITC Staining Kit (Abcam, Cambridge, UK). Three days post plasmid transfection (dpt), EPC cells were incubated with FITC-IETD-FMK or FITC-LEHD-FMK, which irreversibly binds to activated caspase-8 or -9 in apoptotic cells. After incubation for 1 hour at room temperature, cells were washed twice with wash buffer and subsequently trypsinized, centrifuged, and resuspended in wash buffer and were subsequently subjected to quantification by flow cytometry using Guava easyCyte ${ }^{\mathrm{TM}}$ Flow Cytometer (Merck Millipore) and InCyte ${ }^{\mathrm{TM}}$ software version 0.2 (Merck Millipore). These measurements were carried out in 3 independent experiments.

\subsection{Statistical Analysis}

For the quantification of p-eIF2 $\alpha$ and for the caspase assays, one-way analysis of variance was used to test for differences between transfected and non-transfected cells using GraphPad Prism 5.0 (GraphPad Software Inc., La Jolla, CA, USA). 


\section{Results}

\subsection{Carp PKR Overexpression Induce eIF2 $\alpha$ Phosphorylation in EPC Cells}

To determine the ability of PKR to phosphorylate eIF2 $\alpha$ in piscine cells, we overexpressed the wild type wtPKR and the catalytically inactive mutant mutPKR in EPC cells. WB analysis showed that mutPKR was expressed as early as $16 \mathrm{hpt}$ and expression levels continued to increase until $40 \mathrm{hpt}$. Conversely, PKR from the wtPKR transfected cells was not detectable by WB (Figure 1). Further wtPKR expression resulted in phosphorylation of eIF2 $\alpha$ in EPC cells seen as strong phosphorylation of eIF2 $\alpha$ at $16 \mathrm{hpt}$ (Figure 1). Phosphorylation levels decreased at $24 \mathrm{hpt}$ and dropped to similar levels as with negative control (non-transfected) at $40 \mathrm{hpt}$, considered as background levels. In contrast, mutPKR did not result in phosphorylation of eIF $2 \alpha$ above background levels (Figure 1 ). $\beta$-actin was used to normalize the level of p-eIF $2 \alpha$ phosphorylation for three independent experiments. A positive control (infection with infectious pancreatic necrosis virus) was included to demonstrate typical eIF $2 \alpha$ phosphorylation as a result of virus infection (Supplementary Figure S1).

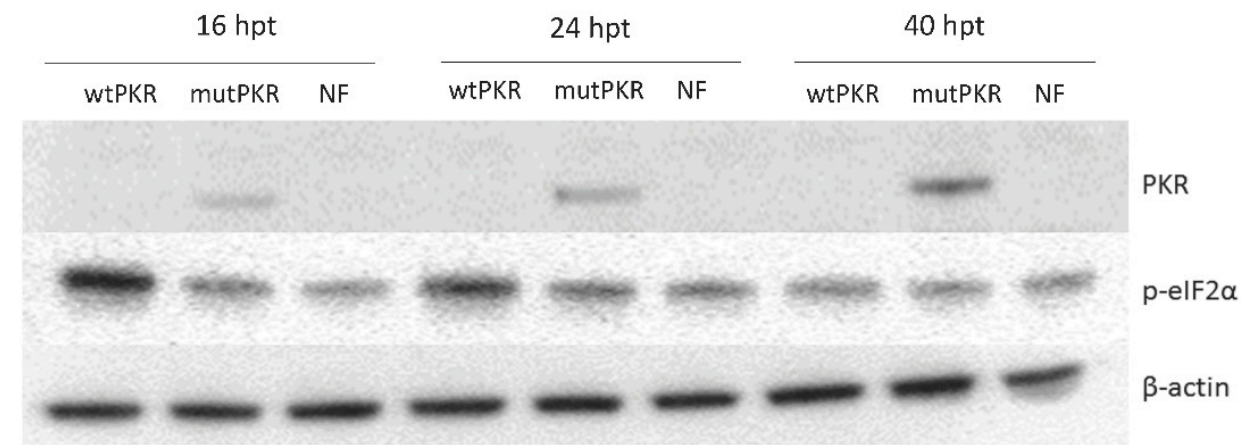

Figure 1. Expression of protein kinase R (PKR), phosphorylated eIF $2 \alpha$ (p-eIF2 $\alpha$ ), and $\beta$-actin in Epithelioma papulosum cyprini (EPC) cells transfected with the wild type pcDNA-wtcarpPKR (wtPKR) and mutant pcDNA-mutcarpPKR (mutPKR), respectively. Negative control, non-transfected cells, were NF. Samples were analyzed at three time-points, 16, 24, and $40 \mathrm{~h}$ post transfection (hpt). PKR was not detected at any time point in wtPKR transfected cells, but positive in mutPKR cells, progressively increasing from 16 to $40 \mathrm{hpt}$. eIF $2 \alpha$ was phosphorylated wtPKR cells, decreasing from 16 to $40 \mathrm{hpt}$. No difference in the phosphorylation levels of eIF $2 \alpha$ between mutPKR and NF. $\beta$-actin was expressed at the same level from all samples at all sampling points.

p-eIF2 $\alpha$ was quantified using a Typhoon imager and expressed relative to $\beta$-actin (normalized) for each experiment. mutPKR was not different from non-transfected cells at any time point post transfection (Figure 2). 


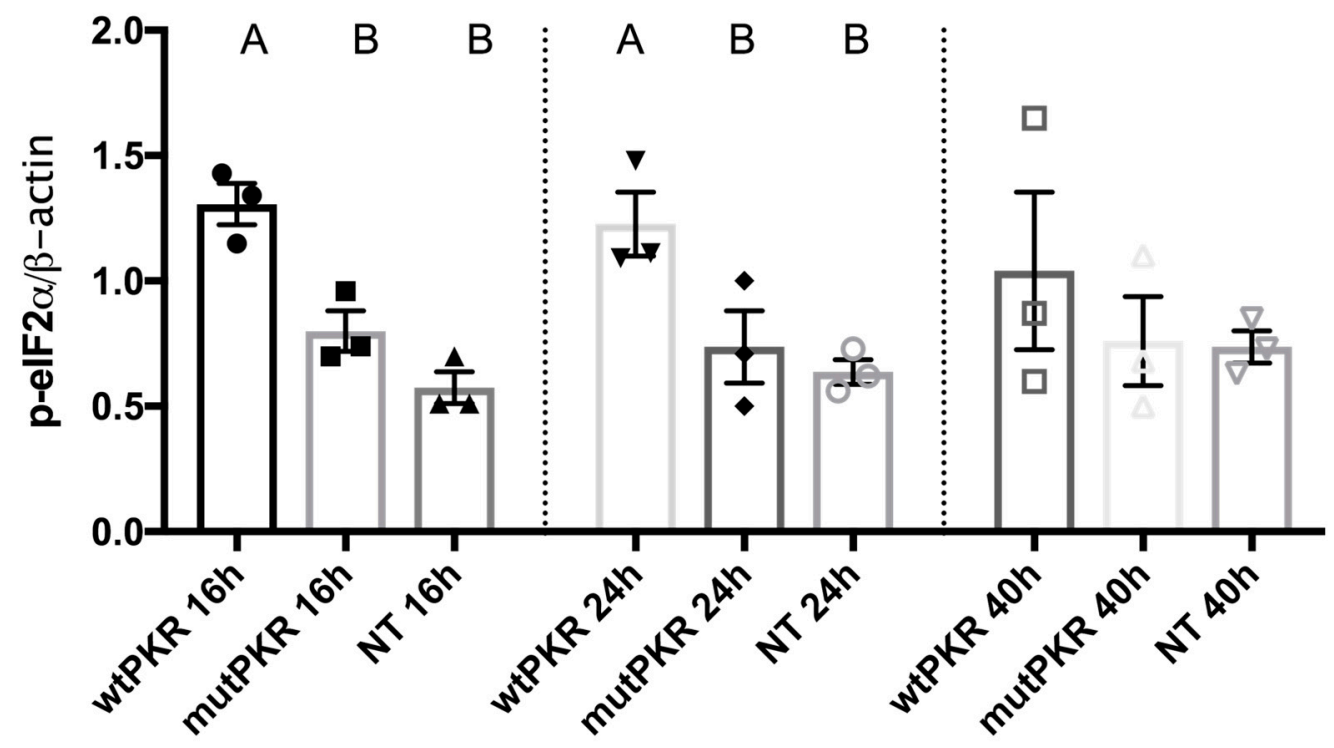

Figure 2. Quantification of eIF2 $\alpha$ phosphorylation after transfection of pcDNA-wtPKR and pcDNA-mutPKR, and non-transfected controls in EPC and AGK cells at different time. p-eIF2 $\alpha$ is measured by densitometry, expressed relative to $\beta$-actin. Representative data from three independent experiments are shown (mean $\pm \mathrm{SEM}, n=3$ ). The different letters above the bars indicate significant differences $(p<0.05)$, and the different shapes on top of the columns indicate individual measurements. No differences were found at $40 \mathrm{~h}$.

\subsection{Carp PKR Overexpression Induce Apoptosis in EPC}

The cellular responses to overexpression of PKR in EPC cells were first assessed morphologically by comparing responses post transfection for wtPKR, mutPKR, and pcDNA3.1 (control) plasmids. There was distinct cell death in the wtPKR transfected cells at $72 \mathrm{~h}$ post transfection (hpt) (Figure 3a) while cells transfected with mutPKR did not show CPE and the cell monolayer was confluent and similar to cells transfected with the negative control (pcDNA3.1 plasmid), all observed at $3 \mathrm{dpt}$. To better understand the basis for the morphological changes observed, transfected cells were prepared for Annexin V/PI Staining followed by flow cytometry analysis, and we found that wtPKR transfected cells had about $10 \%$ apoptotic cells, annexinV-positive and PI-negative, in contrast to mutPKR and pcDNA3.1 controls that both had less than 5\% apoptotic fluorescent cells (Figure 3b). Thus, overexpression of PKR results in induction of apoptosis while catalytically inactive PKR (mutPKR variant) did not result in cell death in EPC cells.

(a)



wtPKR

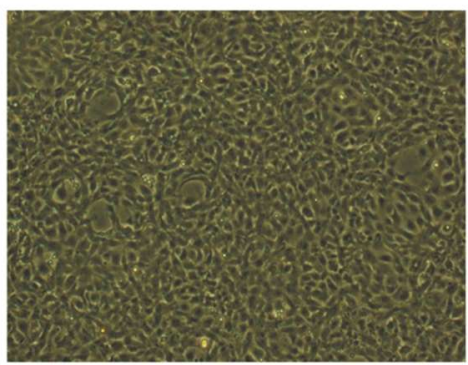

mutPKR

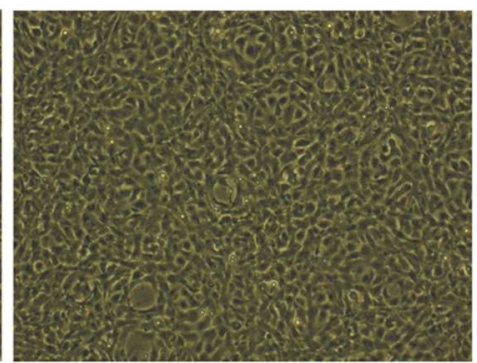

pCDNA3.1-myc-His

Figure 3. Cont. 
(b)

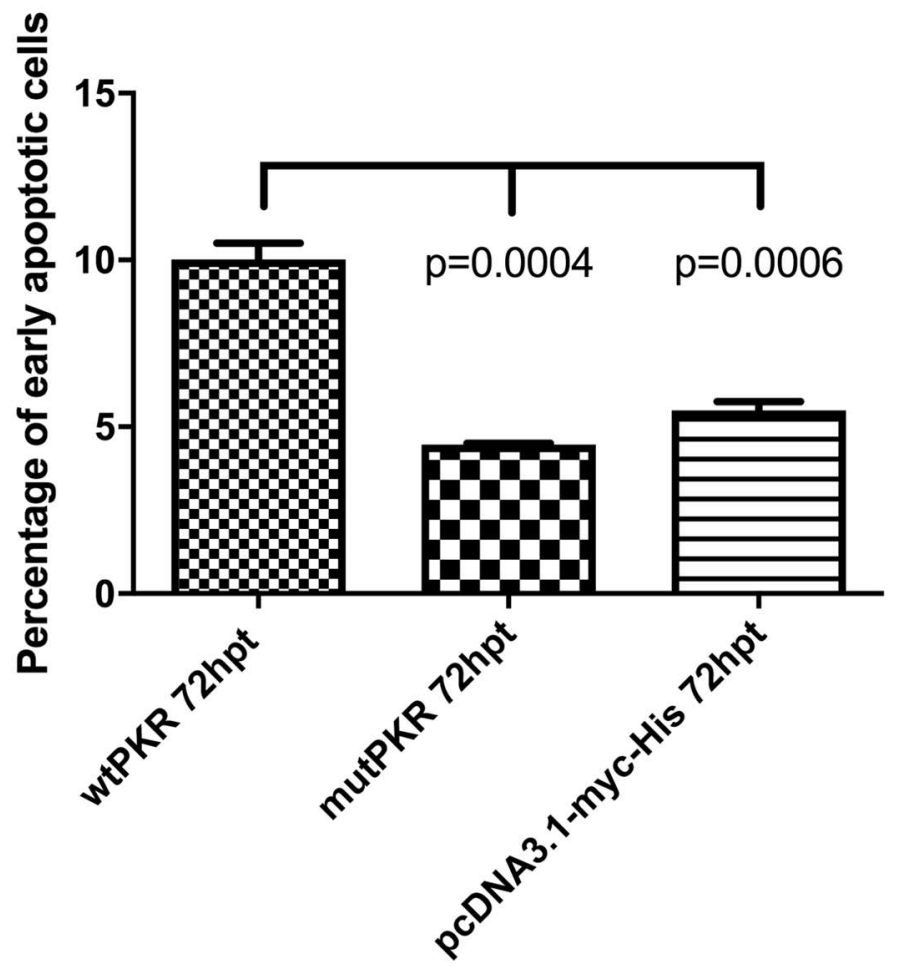

Figure 3. Cytopathic effects (CPE) and the percentage of apoptotic cells in EPC cells transfected with the wtPKR, mutPKR, and pcDNA3.1-myc-His plasmids (controls), respectively, $72 \mathrm{~h}$ post transfection. (a) Distinct CPE in cells transfected with the wtPKR. Cells transfected with mutPKR and pcDNA3.1-myc-His had insignificant CPE and both showing confluent monolayers, $72 \mathrm{~h}$ post transfection. Bar $=10 \mu \mathrm{m}$. (b) Flow cytometry analysis of Annexin V-Fluos and propidium iodide staining of apoptotic cells at $72 \mathrm{~h}$ post transfection. Each bar represents the average results of two independent experiments, three replicates in each. Percentage apoptotic cells in the wtPKR transfected cells was two-fold higher than in mutPKR cells $(p=0.0004)$ and compared to empty plasmid control, at 3 days post transfection (dpt). There was no significant difference between mutPKR and pcDNA3.1-myc-His transfected cells.

\subsection{Caspas-8 and -9 Are Activated in PKR-Induced Apoptosis}

On this basis, we went on to elucidate the underlying mechanisms of cell death, with a focus on receptor-mediated (extrinsic) or mitochondrial (intrinsic) pathway-induced apoptosis. With an aim to differentiate between the two pathways we measured activation of caspase- 8 and -9 in EPC cells transfected with the different plasmids, and again cellular responses by flow cytometry. When incubated with FITC-IETD-FMK (caspase-8) or FITC-LEHD-FMK (caspase-9), we found increased fluorescence intensities for both caspase-8 and -9 in wtPKR transfected cells (Figures 4 and 5). This is in contrast to the mutPKR transfected cells that had a fluorescence intensity level not different from the non-transfected cells (Figure 4). Quantitatively, we found $18.9 \%$ caspase-8 positive cells and $16.1 \%$ caspase-9 positive EPC cells in the wtPKR group. This was significantly higher than the non-transfected cells (Figure 5). Conversely there were 6.17\% activated caspase- 8 and $6.19 \%$ activated caspase-9 positive EPC cells in the mutPKR transfected cells that were not significantly different from the non-transfected control cells, indicating that mutational changes in the catalytically inactive mutPKR could have reduced the ability of PKR to activate caspase- 8 and -9 (Figure 5). 

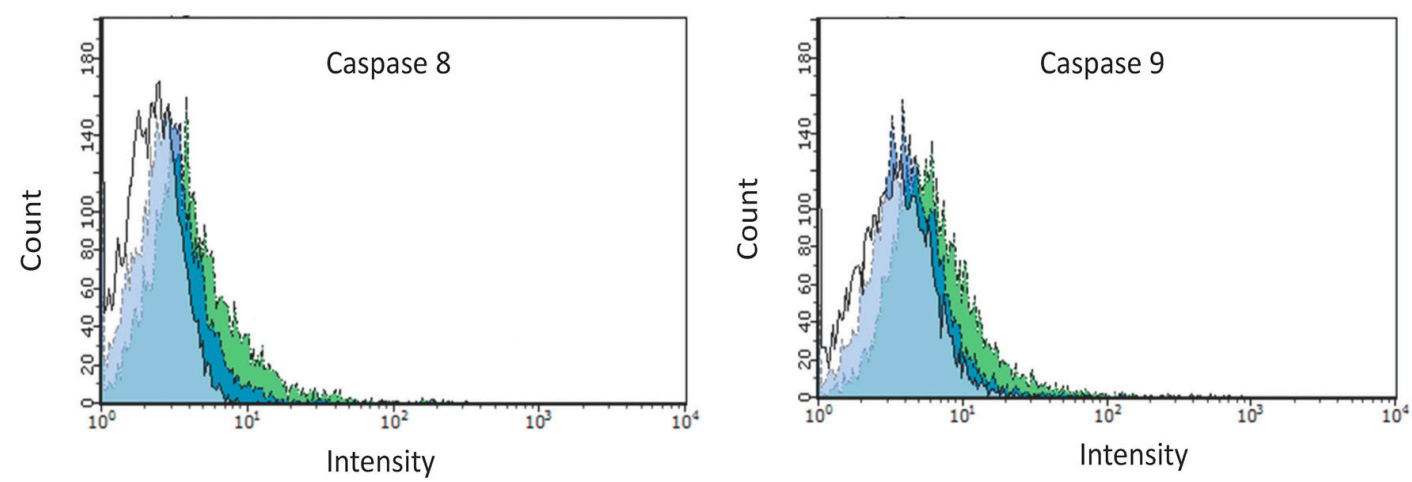

Figure 4. Activated caspase- 8 and -9 positive cells were analyzed by flow cytometry at 3 days post transfection. Representative histogram showing the increase in caspase- 8 and -9 staining in mutPKR (blue) and wtPKR (green) transfected cells relative to non-transfected control cells (white, in front).
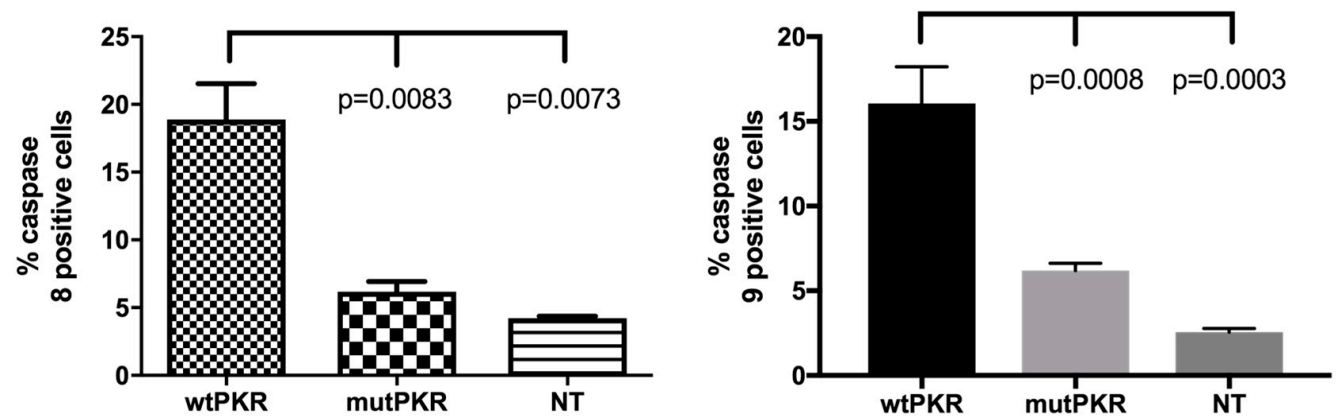

Figure 5. Percentage activated caspase- 8 positive cells was about three-fold higher in the wtPKR transfected cells than in mutPKR cells $(p=0.0083)$, while activated caspase- 9 was 2.5 -fold higher in wtPKR compared to mutPKR transfected cells $(p=0.0008)$. The $p$-values for wtPKR versus non-transfected (NT) are also shown while $p$ values for mutPKR versus NT were both $>0.05$.

\section{Discussion}

Here we show that overexpression of PKR in absence of a virus infection results in phosphorylation of eIF $2 \alpha$ and induction of apoptosis that also involves activation of caspase- 8 and -9. Overexpression of a catalytic domain mutated variant of PKR does not result in eIF $2 \alpha$ phosphorylation and no induction of apoptosis.

Our findings are corroborated by several studies that have shown that PKR overexpression induces eIF2 $\alpha$ phosphorylation in the absence of viral infection or introduction of exogenous dsRNA [15,32,33]. Koromilas et al. [33] showed that overexpression of PKR in NIH 3 T3 mouse cells resulted in increased elF2a phosphorylation that led to increased cell death, while Chong et al. [34] showed that PKR overexpression led to increased eIF $2 \alpha$ phosphorylation resulting in growth suppression of yeast cells. In fish cells, Liu et al. [15] showed that PKR overexpression in Carassius auratus blastula embryo cells $(\mathrm{CAB})$ increased eIF2 $\alpha$ phosphorylation in the absence of exogenous dsRNA but these authors did not study cell death of apoptosis induction.

PKR was not detected in the wtPKR transfected cells unlike the mutPKR transfected cells that efficiently expressed high PKR levels detected by WB. This is in line with Barber et al. who also observed that PKR was inefficiently expressed from wtPKR transfected green monkey COS- 1 cells (Cercopithecus aethiops) compared to the mutPKR transfected cells that had 30- to 40-fold higher expression levels than wtPKR transfected cell. Protein stability measurements and primer extension analysis showed that PKR expression was autoregulated at mRNA translation level resulting in its inefficient expression in wtPKR transfected cells. They further observed that its regulation was highly affected by mutation either in the catalytic or $\mathrm{N}$-terminal regulatory domains resulting in high expression levels in the catalytic inactive form but was inefficiently expressed in the wild type form 
due to mRNA translation autoregulation. Different scientists have reported similar autoregulation of PKR mRNA translation in different cell lines [34-37]. It is likely that the mutation from Lys 419 to $\mathrm{Arg}_{419}$ introduced in the catalytic domain of the mutPKR variant used in this study increased the expression of PKR detected by WB, while the low expression levels detected in the wtPKR were due to autoregulation of mRNA translation of PKR. Furthermore, this suggests that the regulatory mechanisms involved in controlling PKR expression are conserved across the vertebrate taxa.

We have previously used the Annexin V/propidium iodide staining method to detect apoptosis after infectious pancreatic necrosis virus infection in fish cells [38]. However, unlike previous studies that link PKR-mediated apoptosis with viral infections $[39,40]$ in mammalian cells, in the current study we show for the first time that PKR overexpression induces apoptosis without viral infection in fish cells.

Finally, it has been shown in mammalian cells that eIF2 $\alpha$ phosphorylation by PKR leads to activation of caspase- 8 that causes apoptosis via FADD [41] and caspase-9 that uses cytochrome-c and Apaf1 to induce cell death [18,42]. To our knowledge, there are no studies shown to link PKR induced apoptosis with the caspase- 8 and -9 pathways in fish cells. To address this, we compared caspase- 8 and -9 activation levels in the wtPKR transfected cells with mutPKR transfected cells. Our findings show that both caspase- 8 and -9 were significantly activated in the wtPKR transfected cells, which corresponded with a highly significant increase in CPE. On the contrary, mutPKR transfected cells had no increase in the activation levels of caspase- 8 and -9 being similar with the non-transfected control cells that had no CPE. Therefore, these findings suggest that apoptosis detected in the wtPKR transfected cells was induced by PKR via the caspase- 8 and -9 pathways. In these studies, we did not include a chemical that induces apoptosis (like staurosporine [38]) and results should be viewed in this light. The high percentage of apoptotic cells and the contrasting findings relative to mutPKR and controls are in support of our view that the differences observed between wtPKR and the mutated forms clearly shows that overexpression of PKR induces apoptosis in the cell line tested and that the catalytically active domain plays a role in these processes. The fact that these studies were repeated with the same outcome are in favor of our interpretation.

In summary, these data suggest that PKR induced apoptosis via the caspase- 8 and -9 pathways is a conserved cell death mechanism among vertebrates. Future studies should seek to consolidate these findings using gene-editing tools such as the CRISPR-Cas9 or TALEN technologies in order to underpin the functional roles of the individual genes involved in the apoptosis signaling pathway induced by PKR in fish cells.

Supplementary Materials: The following are available online at http:/ /www.mdpi.com/1999-4915/10/10/526/ s1. Figure S1: eIF2 $\alpha$ phosphorylation in CHSE-214 cells following IPN virus infection as positive control.

Author Contributions: Conceptualization, H.M.M. and Ø.E.; Methodology, C.X., A.A.A.G.; Formal Analysis, C.X., A.A.A.G., H.M.M.; Investigation, X.C., A.A.A.G.; Writing-Original Draft Preparation, X.C., A.A.A.G.; Writing-Review \& Editing, Ø.E.; Visualization, A.A.A.G and Ø.E.; Supervision, H.M.M., Ø.E.; Funding Acquisition, Ø.E.

Acknowledgments: The project was partly financed by the Nanoparticle encapsulation of plant-based vaccines against piscine reovirus Norwegian Research Council Project number 239140, and partly by the project Virus vaccines Norwegian Research Council Project number 237315.

Conflicts of Interest: The authors declare no conflict of interest.

\section{References}

1. Perry, A.K.; Gang, C.; Zheng, D.; Hong, T.; Cheng, G. The host type I interferon response to viral and bacterial infections. Cell Res. 2005, 15, 407-422. [CrossRef] [PubMed]

2. De Weerd, N.A.; Samarajiwa, S.A.; Hertzog, P.J. Type I interferon receptors: Biochemistry and biological functions. J. Biol. Chem. 2007, 282, 20053-20057. [CrossRef] [PubMed]

3. Xu, C.; Evensen, Ø.; Munang'andu, H.M. A de novo transcriptome analysis shows that modulation of the JAK-STAT signaling pathway by salmonid alphavirus subtype 3 favors virus replication in macrophage/dendritic-like TO-cells. BMC Genom. 2016, 17, 390. [CrossRef] [PubMed] 
4. Taniguchi, T.; Takaoka, A. The interferon- $\alpha / \beta$ system in antiviral responses: A multimodal machinery of gene regulation by the IRF family of transcription factors. Curr. Opin. Immunol. 2002, 14, 111-116. [CrossRef]

5. Garcia, M.; Gil, J.; Ventoso, I.; Guerra, S.; Domingo, E.; Rivas, C.; Esteban, M. Impact of protein kinase PKR in cell biology: From antiviral to antiproliferative action. Microbiol. Mol. Biol. Rev. 2006, 70, 1032-1060. [CrossRef] [PubMed]

6. Feng, G.; Chong, K.; Kumar, A.; Williams, B. Identification of double-stranded RNA-binding domains in the interferon-induced double-stranded RNA-activated p68 kinase. Proc. Natl. Acad. Sci. USA 1992, 89, 5447-5451. [CrossRef] [PubMed]

7. McCormack, S.J.; Thomis, D.C.; Samuel, C.E. Mechanism of interferon action: Identification of a RNA binding domain within the N-terminal region of the human RNA-dependent P1/eIF-2 $\alpha$ protein kinase. Virology 1992, 188, 47-56. [CrossRef]

8. Dey, M.; Cao, C.; Dar, A.C.; Tamura, T.; Ozato, K.; Sicheri, F.; Dever, T.E. Mechanistic link between PKR dimerization, autophosphorylation, and eIF2 $\alpha$ substrate recognition. Cell 2005, 122, 901-913. [CrossRef] [PubMed]

9. Lee, S.B.; Esteban, M. The interferon-induced double-stranded RNA-activated human p68 protein kinase inhibits the replication of vaccinia virus. Virology 1993, 193, 1037-1041. [CrossRef] [PubMed]

10. Srivastava, S.P.; Kumar, K.U.; Kaufman, R.J. Phosphorylation of eukaryotic translation initiation factor 2 mediates apoptosis in response to activation of the double-stranded RNA-dependent protein kinase. J. Biol. Chem. 1998, 273, 2416-2423. [CrossRef] [PubMed]

11. Zhu, R.; Zhang, Y.B.; Zhang, Q.Y.; Gui, J.F. Functional domains and the antiviral effect of the double-stranded RNA-dependent protein kinase PKR from Paralichthys olivaceus. J. Virol. 2008, 82, 6889-6901. [CrossRef] [PubMed]

12. Rothenburg, S.; Deigendesch, N.; Dey, M.; Dever, T.E.; Tazi, L. Double-stranded RNA-activated protein kinase PKR of fishes and amphibians: Varying the number of double-stranded RNA binding domains and lineage-specific duplications. BMC Biol. 2008, 6, 12. [CrossRef] [PubMed]

13. Hu, C.Y.; Zhang, Y.B.; Huang, G.P.; Zhang, Q.Y.; Gui, H.F. Molecular cloning and characterisation of a fish PKR-like gene from cultured CAB cells induced by UV-inactivated virus. Fish Shellfish Immunol. 2004, 17, 353-366. [CrossRef] [PubMed]

14. Zenke, K.; Nam, Y.K.; Kim, K.H. Molecular cloning and expression analysis of double-stranded RNA-dependent protein kinase (PKR) in rock bream (Oplegnathus fasciatus). Vet. Immunol. Immunopathol. 2010, 133, 290-295. [CrossRef] [PubMed]

15. Liu, T.-K.; Zhang, Y.-B.; Liu, Y.; Sun, F.; Gui, J.-F. Cooperative roles of fish protein kinase containing Z-DNA binding domains and double-stranded RNA-dependent protein kinase in interferon-mediated antiviral response. J. Virol. 2011, 85, 12769-12780. [CrossRef] [PubMed]

16. Gamil, A.A.; Xu, C.; Mutoloki, S.; Evensen, O. PKR Activation Favors Infectious Pancreatic Necrosis Virus Replication in Infected Cells. Viruses 2016, 8, 173. [CrossRef] [PubMed]

17. Hu, Y.S.; Li, W.; Li, D.M.; Liu, Y.; Fan, L.H.; Rao, Z.C.; Lin, G.; Hu, C.Y. Cloning, expression and functional analysis of PKR from grass carp (Ctenopharyngodon idellus). Fish Shellfish Immunol. 2013, 35, 1874-1881. [CrossRef] [PubMed]

18. Wang, X. The expanding role of mitochondria in apoptosis. Genes Dev. 2001, 15, 2922-2933. [PubMed]

19. Schmitz, I.; Kirchhoff, S.; Krammer, P.H. Regulation of death receptor-mediated apoptosis pathways. Int. J. Biochem. Cell Biol. 2000, 32, 1123-1136. [CrossRef]

20. Locksley, R.M.; Killeen, N.; Lenardo, M.J. The TNF and TNF receptor superfamilies: Integrating mammalian biology. Cell 2001, 104, 487-501. [CrossRef]

21. Kischkel, F.; Hellbardt, S.; Behrmann, I.; Germer, M.; Pawlita, M.; Krammer, P.; Peter, M. Cytotoxicity-dependent APO-1 (Fas/CD95)-associated proteins form a death-inducing signaling complex (DISC) with the receptor. EMBO J. 1995, 14, 5579-5588. [CrossRef] [PubMed]

22. Chinnaiyan, A.M. The apoptosome: Heart and soul of the cell death machine. Neoplasia 1999, 1, 5-15. [CrossRef] [PubMed]

23. Schimmer, A.D. Inhibitor of apoptosis proteins: Translating basic knowledge into clinical practice. Cancer Res. 2004, 64, 7183-7190. [CrossRef] [PubMed]

24. Elmore, S. Apoptosis: A review of programmed cell death. Toxicol. Pathol. 2007, 35, 495-516. [CrossRef] [PubMed] 
25. Cohen, G.M. Caspases: The executioners of apoptosis. Biochem. J. 1997, 326, 1-16. [CrossRef] [PubMed]

26. Slee, E.A.; Adrain, C.; Martin, S.J. Executioner caspase-3,-6, and-7 perform distinct, non-redundant roles during the demolition phase of apoptosis. J. Biol. Chem. 2001, 276, 7320-7326. [CrossRef] [PubMed]

27. Xu, C.; Evensen, Ø.; Munang'andu, H.M. De novo assembly and transcriptome analysis of Atlantic salmon macrophage/dendritic-like TO cells following type I IFN treatment and Salmonid alphavirus subtype-3 infection. BMC Genom. 2015, 16, 96. [CrossRef] [PubMed]

28. Sun, S.; Ge, X.; Zhu, J.; Zhang, W.; Zhang, Q. Molecular cloning, immunohistochemical localization, characterization and expression analysis of caspase- 8 from the blunt snout bream (Megalobrama amblycephala) exposed to ammonia. Fish Shellfish Immunol. 2015, 47, 645-654. [CrossRef] [PubMed]

29. Espín, R.; Roca, F.J.; Candel, S.; Sepulcre, M.P.; González-Rosa, J.M.; Alcaraz-Pérez, F.; Meseguer, J.; Cayuela, M.L.; Mercader, N.; Mulero, V. TNF receptors regulate vascular homeostasis in zebrafish through a caspase-8, caspase-2 and P53 apoptotic program that bypasses caspase-3. Dis. Model Mech. 2013, 6, 383-396. [CrossRef] [PubMed]

30. He, B.-L.; Yuan, J.-M.; Yang, L.-Y.; Xie, J.-F.; Weng, S.-P.; Yu, X.-Q.; He, J.-G. The viral TRAF protein (ORF111L) from infectious spleen and kidney necrosis virus interacts with TRADD and induces caspase 8-mediated apoptosis. PLoS ONE 2012, 7, e37001. [CrossRef] [PubMed]

31. Chen, L.; Evensen, O.; Mutoloki, S. Delayed protein shut down and cytopathic changes lead to high yields of infectious pancreatic necrosis virus cultured in Asian Grouper cells. J. Virol. Methods 2014, 195, 228-235. [CrossRef] [PubMed]

32. Dagon, Y.; Dovrat, S.; Vilchik, S.; Hacohen, D.; Shlomo, G.; Sredni, B.; Salzberg, S.; Nir, U. Double-stranded RNA-dependent protein kinase, PKR, down-regulates CDC 2/cyclin B 1 and induces apoptosis in non-transformed but not in v-mos transformed cells. Oncogene 2001, 20, 8045-8056. [CrossRef] [PubMed]

33. Koromilas, A.E.; Roy, S.; Barber, G.N.; Katze, M.G.; Sonenberg, N. Malignant transformation by a mutant of the IFN-Inducible dsRNA-dependent protein kinase. Science 1992, 257, 1685-1689. [CrossRef] [PubMed]

34. Chong, K.; Feng, L.; Schappert, K.; Meurs, E.; Donahue, T.; Friesen, J.; Hovanessian, A.; Williams, B. Human p68 kinase exhibits growth suppression in yeast and homology to the translational regulator GCN2. EMBO J. 1992, 11, 1553-1562. [CrossRef] [PubMed]

35. McCormack, S.J.; Ortega, L.G.; Doohan, J.P.; Samuel, C.E. Mechanism of interferon action motif I of the interferon-induced, RNA-dependent protein kinase (PKR) is sufficient to mediate RNA-binding activity. Virology 1994, 198, 92-99. [CrossRef] [PubMed]

36. Thomis, D.C.; Samuel, C.E. Mechanism of interferon action: Evidence for intermolecular autophosphorylation and autoactivation of the interferon-induced, RNA-dependent protein kinase PKR. J. Virol. 1993, 67, 7695-7700. [PubMed]

37. Taghavi, N.; Samuel, C.E. RNA-dependent protein kinase PKR and the Z-DNA binding orthologue PKZ differ in their capacity to mediate initiation factor eIF2 $\alpha$-dependent inhibition of protein synthesis and virus-induced stress granule formation. Virology 2013, 443, 48-58. [CrossRef] [PubMed]

38. Gamil, A.A.; Mutoloki, S.; Evensen, Ø. A piscine birnavirus induces inhibition of protein synthesis in CHSE-214 cells primarily through the induction of eIF2 $\alpha$ phosphorylation. Viruses 2015, 7, 1987-2005. [CrossRef] [PubMed]

39. Takizawa, T.; Ohashi, K.; Nakanishi, Y. Possible involvement of double-stranded RNA-activated protein kinase in cell death by influenza virus infection. J. Virol. 1996, 70, 8128-8132. [PubMed]

40. Yeung, M.C.; Chang, D.L.; Camantigue, R.E.; Lau, A.S. Inhibitory role of the host apoptogenic gene PKR in the establishment of persistent infection by encephalomyocarditis virus in U937 cells. Proc. Natl. Acad. Sci. USA 1999, 96, 11860-11865. [CrossRef] [PubMed]

41. Gil, J.; Alcami, J.; Esteban, M. Induction of apoptosis by double-stranded-RNA-dependent protein kinase (PKR) involves the a subunit of eukaryotic translation initiation factor 2 and NF-kappa B. Mol. Cell Biol. 1999, 19, 4653-4663. [CrossRef] [PubMed]

42. Gil, J.; García, M.A.; Esteban, M. Caspase 9 activation by the dsRNA-dependent protein kinase, PKR: molecular mechanism and relevance. FEBS Lett. 2002, 529, 249-255. [CrossRef] 